\title{
Suffering in Medical Contexts: Laughter, Humor, and the Medical Carnivalesque
}

This article argues that a primary context for medical humor is a culture of suffering that permeates the medical profession and suggests that this laughter-suffering connection is part of a broader phenomenon called the medical carnivalesque that is found in medical culture.

\author{
Keywords \\ AFS ETHNOGRAPHIC THESAURUS: Health care, doctors, occupational \\ folklore, black humor, carnivalesque
}

A man takes his sick mother to the Emergency Room. After waiting around for hours and hours in a state of fretfulness and without knowing what's going on, the doctor finally comes out and asks, "Well, do you want the good news first, or the bad news?" Grimly, the man replies, "The bad news."

"Well," says the doctor, "The bad news is that your mother has had a terrible stroke. It's completely incapacitated her. She's basically a vegetable. She'll never be able to feed herself, walk, or talk again."

"Oh my God," says the man, "that's terrible."

"Yes, but unfortunately, there's more," says the doctor. "In addition, to being unable to feed herself, or walk, or talk, she can't wash or take care of her other bodily needs. You will need to do all of these things for her, day and night, and she won't even know it's you."

"Oh my God," says the man, "that's terrible."

"Yes," says the doctor, "You'll be responsible for her every need. The worse news is you'll end up completely physically and emotionally exhausted because you won't be eating or sleeping yourself; you'll also probably end up bankrupt because of the financial burden. In fact, because of the stress, you'll probably die before she does."

"Oh my God," says the man. "What's the good news?"

"HA! Just kidding—she's dead."

I FIRST HEARD THIS JOKE, WHICH HERE I HAVE RECONSTRUCTED from memory, from medical students at Indiana University around the year 2000. My spouse was in medical school at the time, and to be frank, I was somewhat horrified when I first heard it

LISA Gabbert is Associate Professor of Folklore and American Studies in the Department of English at Utah State University 
because it seemed so offensive. I don't think my initial reaction was unusual: physicians tend to find this joke funny, but when I tell it to non-medical people, I am usually met by shocked silence followed by uncomfortable laughter. People then often switch to another topic of conversation.

I have thought a lot about this joke-and medical humor more broadly-since then, and now, 2 decades later, I have finally come to more fully understand what it is about. I initially considered this joke an extreme example of gallows humor, a term sometimes used to characterize the dark or "sick" comic bent for which physicians are well-known (Watson 2011). "Gallows humor," a recent term that dates only to 1901 in English according to the Oxford English Dictionary (OED), is the last word of a man on the gallows, and it is characterized as dark and bitter or grim. ${ }^{1}$

For many years, I also considered it to be an example of a traditional, folkloristic inclination to pair humor and death in absurd situations (Gabbert and Salud 2009). As Peter Narváez' volume Of Corpse aptly illustrates, the pairing of humor, play, joking behavior, and laughter with contexts of death is well-established in a variety of cultures and situations (2003a; see also Miller 2012; Blank 2013). Physicians routinely deal with the specter of death in their training and work, and this explanation seemed logical.

More recently, however, I have concluded that the best way to appreciate this joke in particular, and medical humor more broadly, is to situate it within a larger framework of suffering and laughter. This framework is based on the proposition that suffering is an integral part of medical practice and a feature that permeates the profession. My research suggests first that physicians and other caregivers suffer because of their work and that suffering is an intersubjectively constituted work-related experience. I further argue that suffering permeates medical practice and that it is a cultural, not merely clinical, dimension of medical practice. Finally, I suggest that this culture of suffering is a primary context for medical humor and the medical carnivalesque. As I illustrate below, doctors use humor as an occupational strategy to temporarily reassign the dominant meanings, values, and beliefs normally given to pain, illness, and death, thus shifting the actual experience of work-related suffering by changing its meaning.

That laughter exists in medical contexts is not a new insight. Doctoring is a profession that is stereotyped as having an appreciation for the comic, and the practice of medicine time and again has proved useful fodder for comedy. The House of God by Samuel Shem, for example, is a famous satire about the training and inculcation of medical doctors in an elite East Coast hospital, which was censored by some medical schools when it was published in 1978. It exists alongside a plethora of television comedies such as the classic series $M^{\star} A^{\star} S^{\star} H$, films, websites, blogs, YouTube channels, and actual joking behavior in clinical settings, most famously by the physicianturned-clown Patch Adams. Folklorist Dr. Sabina Magliocco once told me that she had a pretty good joking relationship with her doctor, but at one point, when she was particularly witty, she was told, "You know, you can't be funnier than your doctor."

Scholars from the disciplines of folklore, sociology, medical anthropology, and literature, as well as from the medical profession itself, have attended to the existence of medical humor and the clinical vernacular. As noted above, medical humor is 
considered to be a kind of gallows or "sick" humor, and the most common conclusions are that humor in medicine functions as a way to relieve stress, as a defense mechanism, and/or as a way to create solidarity among medical professionals (Coombs et al. 1993; Parsons et al. 2001; Gordon 1983). Others have suggested that it resists the instrumentality of biomedicine (Burson-Tolpin 1989, 1990), or that it arises around patients that confound categories (George and Dundes 1978; Becker 1993; Winick 2004). Many discussions of humor in the medical field take a pragmatic approach, focusing on whether such humor is ethical (McCrary and Christensen 1993; Watson 2011; Donnelly 1986), whether it creates a negative atmosphere or adversely affects training (Wear et al.2009), whether the risks of humor outweigh the benefits (Berger, Coulehan, and Belling 2004), or whether humor is useful in some way (McCreaddie and Wiggins 2008; Penson et al. 2005; Sobel 2006).

My own contribution to this body of research has been, with co-author and physician Dr. Anton Salud, to coin the term "medical carnivalesque" to describe the inversions, absurdities, and stark, sometimes quite shocking themes and taboos that give medical humor its dark or sick qualities (Gabbert and Salud 2009). Drawing on Bakhtin's work on medieval Carnival and his notion of carnivalesque laughter ([1968] 1984), we suggest that the medical carnivalesque is found in large, modern teaching hospitals and characterized by irreverence: poking fun at much that is considered "sacred" in medicine, such as patients, science, technology, doctors, and the practice of medicine itself. Like Bakhtin's carnivalesque, medical humor contains scatological and sexual themes; references to the body, illness, disease, and death; and is distinguished by profound ambivalence. We theorized that the medical carnivalesque is rooted in the occupational paradoxes of modern medicine-specifically, the biomedical attempt to rationalize and contain death and prolong life at practically all costs, which can result in surreal and absurd situations.

Consider, for example, the passage below, taken from The House of God:

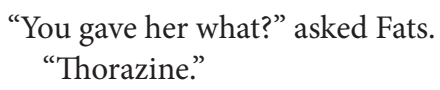

Fats burst into laughter. Big juicy laughs rolled down from his eyes to his cheeks to his chins to his bellies, and he said, "Thorazine! That's why she's acting like a chimp. Her blood pressure can't be more than sixty. Get a cuff. Potts, you're terrific. First day of internship, and you try to kill a gomere with Thorazine." (Shem [1978] 2003:47)

The character known as "Fats" is a senior medical resident tasked with supervising inexperienced interns such as Potts, who has just given an elderly patient improper medication. (The patient is colloquially identified as a "gomere," a slang term first explored by Victoria George and Alan Dundes that describes a-usually male ["gomer"], but in this case female, hence the term "gomere"-elderly patient who is perceived as dirty and debilitated [George and Dundes 1978; see also Leiderman and Grisso 1985].) This mistake, and the unhappy result, is the source of Fats' laughter, which rolls out of him and over the intern in waves. Fats' "juicy" laughter and his "bellies" clearly suggest a carnivalesque element (Gabbert and Salud 2009). The entire book consists of medical bad-boy antics, rule-breaking, and joking behavior, much of which is mediated by the laughter of "the fat man." 
What we did not identify in our previous work and what this paper adds, however, is that suffering is a crucial part of the medical carnivalesque. In The House of God, for example, what is unstated but found throughout the book is the suffering both patients and doctors endure. In the above passage, Fats describes the aggrieved patient as a "gomere" who is "acting like a chimp" because Potts gave her Thorazine, an antipsychotic drug that, in high doses, causes motor difficulties. Potts is an intern, a physician who is by definition inexperienced and underequipped, overworked, abused, sleep-deprived, and emotionally and physically exhausted. The result is an unhappy situation for both patient and doctor, generating laughter and hilarity from Fats.

This scene is only one of many that describe suffering; indeed, The House of God can be read as a novelistic catalog of humorous play that emerges in the context of some of the horrific events that both patients and housestaff endure. These scenes are fiction, but they index an actual culture of suffering that permeates the practice of modern biomedicine. Unfortunately, the suffering of physicians and other caregivers is rarely acknowledged either by themselves or others, and this lack of recognition contributes to this culture of suffering by silencing its existence.

The identification of suffering as a cultural component of medicine is important because the medical humanities seek to understand the field of medicine from a cultural perspective. Many culturally-oriented studies of biomedicine focus on technological, scientific, dualistic, and rationalist perspectives, and explore how such perspectives shape the medical field's values and beliefs, but suffering as a cultural element largely has not been addressed. The field of medicine itself seeks to relieve suffering, and therefore suffering has mostly been treated as an external, clinical phenomenon to be treated in patients. It has not been recognized as a more pervasive and ingrained cultural feature that shapes the experiences of physicians and permeates medical practice in various ways. This culture of suffering undergirds much medical humor and the medical carnivalesque, providing a foundation and explanation for its existence. Studies of medical humor tend to offer functional, Freudian, or neo-Freudian explanations, such as the idea that medical humor functions to release aggression and hostility, to relieve stress and pent-up anxiety, or to act as a coping mechanism. While these interpretations are certainly true, functionalist explanations do not address the underlying causes of the humor itself, nor do they explain its particular qualities.

The pairing of suffering and laughter is commonly viewed in a negative light. By calling a patient a "gomere" and laughing at her behavior as well as the misery of his hapless intern, for example, one might presume that Fats is engaging in the offensive act of schadenfreude, literally translated as "harm-joy" and defined in the OED as "malicious enjoyment of the misfortunes of others." 3 The idea underlying schadenfreude is that laughing at the suffering of others constitutes maliciousness. To laugh at another's suffering is, according to modern sensibilities, unjust, cruel, or even sadistic. It presumably isn't something a moral or good person would do.

This idea that suffering and laughter are incompatible carries over into scholarship. A search through the MLA database reveals only a few articles on suffering and laughter, and none of the articles published in Humor: The International Journal of Humor Research, the primary research journal on humor and laughter, contained the 
word "suffer" or "suffering" in the title at the time this article was drafted in 2018, at least as they were indexed in MLA and JSTOR. The very existence of medical humor has even compelled medical ethicists to ask whether or not such humor is compatible with quality medical care (e.g., McCrary and Christensen 1993). Yet suffering and laughter co-exist in reality, and Fats is not engaging in schadenfreude. He is laughing at the absurdity of the situation in which both patient and physician find themselves, one in which they both suffer and from which neither can easily escape. The identification of suffering as a basis for medical humor helps contextualize the sometimes harsh dimensions of medical humor that can make outsiders (and insiders) uncomfortable. Laughter is an appropriate, albeit seemingly incongruous, response to the very painful but quite human situations that frequently occur in medicine. ${ }^{4}$

\section{To Suffer}

According to the OED, a primary meaning of the verb "to suffer," as indicated by Roman numeral I, implies an experience: "to undergo, endure." (Further in the entry, Roman numeral II lists definitions clustering around the meaning of "to tolerate, allow."5) In the subsequent glosses for Roman numeral I, the OED explains that what one undergoes or endures during suffering is usually "painful, distressing, or injurious." So while suffering evokes something painful, the main aspect of the definition is that it is a particular type of experience.

What type of experience is suffering? What are the constituent elements? Eric Cassell, a physician and professor of medicine and public health, began to explore these questions in the early 1990s ([1991] 2004). He is credited for having raised the awareness of physicians about the complicated nature of suffering. Writing about medical training in the first half of the twentieth century, Cassell noted that doctors traditionally were trained to treat diseases rather than patients ([1991] 2004:7, 10). Rather than looking at the person holistically, physicians treated the disease and straightforwardly presumed that curing the disease would cure the person. Physicians also primarily equated suffering with pain and sought to relieve pain in order to relieve suffering. In contrast, Cassell argued that suffering is an experience made up of a variety of elements, of which pain is but one. Suffering is painful, but Cassell noted that a person can be in great physical pain and not suffer. Pain and suffering therefore are not the same thing; suffering entails more.

The additional elements of suffering that Cassell identified include not only pain but also hopelessness, isolation, shame, dread of the future, and an impending sense of total destruction of the self ([1991] 2004:33-5, 42, 56-7). People who suffer feel alone and isolated; it seems as though there is no one to talk to and that there is no one who shares or can understand the experience. People who suffer also often are ashamed of themselves and/or are ashamed of what they are having to endure-the experience itself is perceived as shameful. This shame then reinforces feelings of isolation, since people who feel shame are not likely to speak about their experiences to others. Sufferers also feel helpless, since they seemingly cannot change their situation, and they feel hopeless because they see no end to the suffering. Finally, a person who suffers often feels that the suffering is meaningless-that there is no reason for it. This 
lack of meaning can engender an existential crisis for the sufferer; he or she feels that the basis of his or her existence has been destroyed or completely rearranged. Clearly, suffering is a phenomenon that goes well beyond medical facts. Cassell argued that physicians wanting to relieve suffering need to treat their patients holistically, since suffering involves a person's entire being: mental, emotional, psychological, and spiritual states, not merely the physical body.

Cassell's work has had an enormous influence on the practice of medicine over the past 30 years. One significant development has been the emergence of the field of palliative care. The World Health Organization describes palliative care as "an approach that improves the quality of life of patients and their families facing the problem associated with life-threatening illness, through the prevention and relief of suffering by means of early identification and impeccable assessment and treatment of pain and other problems, physical, psychosocial and spiritual."6 In other words, palliative care treats suffering holistically. Yet even with a modern, expanded view of the holistic nature of suffering, the field of medicine still situates suffering within a clinical perspective: suffering is conceptualized as a problem to be solved in treating patients. Suffering is not considered apart from immediate patient care, meaning that little consideration is given to how it operates or is positioned within medicine systemically.

One way suffering operates systemically is vis-à-vis the suffering health care providers may endure as part of their everyday work: they work in difficult conditions; they are witnesses to the suffering of their patients; and they are tasked with the difficult job of relieving or eliminating suffering, making suffering an internal and pervasive feature of the profession. Suffering therefore is constitutive of medical practice; it is not solely a clinical condition to be addressed in individual patients.

My research has been and continues to be based on personal experience as the spouse of a physician, as well as library research and fieldwork conducted over a number of years. I first recognized that medicine had its own body of occupational folklore when my husband entered medical school at Indiana University in 1999, and I began collecting folklore-related items at that time. In the intervening years, I have lived through the rigors of his intern year, residency, and a fellowship in pulmonary critical care at the University of Utah, an intense training period that lasted 11 years. During that time, I have met, socialized with, and become good friends with physicians representing a wide variety of specializations from all over the country and their families, and conversation in social situations often turns to work and stories about work. I began a more in-depth phase of research when I interviewed medical students in 2012, and I have since conducted additional, sporadic interviews with physicians across a variety of specialties in Utah and New York, work that is still ongoing. I also spent 2 days doing observations in the operating rooms (OR) at the University of Utah Hospital on June 20, 2016, and August 1, 2016.

This research has focused on medical students and doctors, so I am unable to comment on the experiences of suffering and its relation to humor among nurses and other health care providers. But the reality of the suffering of physicians hit home to me during those 2012 interviews with medical students at a school in the Midwest. The original purpose of those interviews was to discover whether or not students 
had become more sympathetic to their patients' suffering as a result of sensitivity training. What I found was not a lack of sympathy to patient suffering, but rather that the terrible conditions of their patients greatly affected and even traumatized these bright and idealistic young people. Students told heart-wrenching stories about how the suffering of their patients directly affected them on a daily basis. ${ }^{7}$ One fourth-year medical student, for example, told me about one of her patients who was dying from complications related to HIV. The man had recently moved to the area to be with his girlfriend, but she had broken up with him. He was poor, and he had no family nearby. This student was so overcome by his case that she nearly purchased a plane ticket with her own money so that he could go home to see his friends and family one last time before he died. She cried at his bedside over his situation. The interview excerpt below, as well as the others in this article, has been edited lightly for readability.

I suppose the intense situations that uh, I would frequently see really sick dying people. ... I did see one person who I knew had a very very short life expectancy while I was on internal medicine that really affected me. He was, I think in his $40 \mathrm{~s}$ and he had lived for probably 20 years with HIV and had ... what ... he was pretty much end-stage liver failure and had a 6-month outlook. And it was very sad to me because he had moved to [Midwestern city] to be with a woman who also had HIV and I guess they had kind of broken up but she was still supporting him, and all of his family and friends were really in New York. And he was too poor, really, to afford a trip back to New York. And I seriously considered buying him a plane ticket to New York so he could go see his family and friends one more time before dying. It was very very hard for me to think about being somewhere where you didn't have that many connections and really wanting to see people one last time. (Anonymous 2012d)

It was particularly hard for students to see children die. One student told me about a child who had a number of medical problems, including dwarfism. The child's mother was unequipped to care for him, and he spent several extra weeks in the hospital before his grandmother agreed to take him home. When the medical student returned to the rotation, the child was back in the ICU, had been living in foster care, and was in a severe state of septic shock. They had to remove most of his bowel, and he died.

The same medical student quoted above told another story about a baby whose death greatly affected her:

I think that some of the things that make it hard is when the people themselves aren't - who are having these horrible things happen to them-aren't expecting it and aren't ready for it. For instance, when I did the pediatric stuff, it was just so hard to see the children die and see their family, when it was someone who had been previously healthy or everything had been going around like normal. For instance, there was a child who had been born who after a normal, uncomplicated pregnancy, had great Apgar scores, like probably 7 and 9 or something like that, and then, 2 hours or 3 hours after birth, the baby started crashing and nobody knew why. So the baby was transferred to our pediatric intensive care unit and put on ... support actually, and just everything we did didn't help.... It was just so hard to see that family because they, they had no idea this was coming. Everything had seemed perfect and happy and before they withdrew support they, they took a few minutes to dress the baby 
up, take some pictures, and hold her, which was something they hadn't really been able to do. And it's just such a surprise to them that, that they had this, this horrible thing happen. (Anonymous 2012d)

Kahn and Steeves outline eight aphorisms of suffering, one of which is that "the experience of suffering . . includes . . the caring of others" (1995:13). As an intersubjective experience, the witnessing of suffering can lead to suffering on the part of the witness, an idea that was borne out in interviews. Students often lost sleep after having to work intimately with people in unhappy, tragic, and hopeless situations.

Further contributing to their suffering was the fact that physicians are expected as part of their job to solve the problem, or at least to render some relief. The official roles of medical students were that of "caregiver," and "student-physician," roles that presume their competence and ability to help and/or heal. Doctors are by definition responsible for their patients, and these students perceived themselves as being responsible for improving their patients' lives if possible. The reality, however, was quite different: students quickly discovered how limited they were in their ability to help others effectively. Many patients were simply too sick or had complicated social or psychological problems for which the practice of medicine is unequipped to deal. As intelligent, idealistic young people accustomed to achieving a certain degree of success, these medical students were confronting for the first time not only the realities of the modern Western health care system but also their own limitations. Learning the harsh realities of medical practice engendered feelings of frustration, heartsickness, shame about their own perceived inadequacies, and powerlessness in their dealings with illness. The relationship between doctor and patient is quite intimate, even if it appears clinical, and such experiences triggered significant losses of idealism, faith in science, and confidence in their own abilities. Several students told me that they couldn't talk about these horrific experiences with their friends, parents, or spouses because they felt that no one but other medical students would really understand "what was going on," thus contributing to feelings of isolation and loneliness. Together, these feelings of futility, loneliness, isolation, physical exhaustion from food and sleep deprivation, a feeling that nobody else understands what is going on, shame for being unable to help, a crisis of identity, and a sense that it will never end clearly constitute suffering according to Cassell's criteria. The experience of confronting serious illness, death, and tragedy over and over again - and being professionally responsible for curing, staving off, or offering relief from them-can, for some caregivers, cause personal suffering. ${ }^{8}$

Few medical students and doctors describe training and work experiences in terms of trauma and suffering. This is likely because there are multiple, deeply ingrained social and cultural injunctions against talking about provider suffering: apparently, it is a taboo topic. The first injunction comes from the occupational culture of care providers. As a physician, it would be unseemly and unprofessional to focus on one's own state when one's patients are clearly in worse condition. As noted by Meier, Back, and Morrison, "in the idealized professional model, the needs and interests of the patient are intended to be the sole focus of the relationship and ... physicians' feelings are extraneous" (2001:3,007). Focusing on himself is exactly what Fats does in 
House of God when he advises Potts about the third (satirical) "law" of medicine: "At a cardiac arrest, the first procedure is to take your own pulse" (Shem [1978] 2003:40), but this law is funny exactly because it directly contradicts the official directive to care for one's patients first. It of course also contains, like much humor, an element of truth and/or good advice.

There is also an informal code of endurance among physicians that impels workers to downplay or ignore their own physical and mental discomfort in their duties as caregivers. Hospital staff will go into work when sick, for example, rather than calling in ill, as doing so (unless one is infectious) can be deemed a sign of weakness. Compared to sick patients with severe, perhaps life-threatening problems, a physician's cold, fatigue, or even depression is considered unimportant, and staff learn to ignore their own physical limitations and well-being. When my spouse went through internal medicine residency at the University of Utah beginning in 2004, I discovered that it was not infrequent, for example, for overworked and slightly sick residents to give themselves bags of IV fluids in order to rapidly hydrate so that they might keep working. Semiotically, staff are paid health care providers and not patients, so by definition they can't be sick; being sick, with the possibility of being re-categorized as "patient," unsettles their identity and role as care providers.

A final reason why physicians and other staff tend to ignore their own sickness has to do with the organization of hospital work. Taking care of sick people is not work that goes away or can be ignored; someone must always be there to take care of the patients. When a physician calls in sick, his or her co-workers are forced to work harder because they then must not only do their own work, but also the sick physician's undone work. Taking time for one's physical or psychological needs increases the already heavy workload of one's co-workers and therefore is always at their expense, making most physicians quite reluctant to take time away from work for themselves.

Another injunction against talking about provider suffering comes from humanities-oriented medical research in academia. In folklore studies, the discipline eventually moved beyond item-centered examples and notions that folk medicine was found only among rural, uneducated "folk" to highlight the perspectives and experiences of patient health care beliefs and practices among all populations, a patient-centered approach pioneered by David Hufford $(1994,1998)$ and Bonnie O'Connor (1994). Folklore studies generally attend to folk or vernacular perspectives, often understood as the perspectives of those lacking power. Because patients lack power when encountering modern medical health care systems, patient-centered approaches were crucial in making marginalized voices heard. The field has since learned that patients are not really entirely powerless but actually make strategic health care choices, drawing from a variety of vernacular, folk, alternative, and official sources (O'Connor and Hufford 2001; Brady 2001) and that they resist conventionalized and scientized medical narratives about disease, treatment, and technology in a variety of ways (Goldstein 2004; Campion-Vincent 2005; Kitta 2012; Lee 2014). Yet with the exception of the above-mentioned studies on medical humor and a few other examples, folklorists have not addressed physician and/or clinical perspectives likely because they are perceived as powerful, while the topic of suffering has not been addressed at all. Charles Briggs (2012) suggested a more holistic folkloristics of health, including 
urging folklorists to "study up," and it is in this spirit that I offer a look at physicians rather than patients.

The topic of provider suffering also is marginalized in the scholarship of the medical field, which has a more extensive body of research on suffering than folklore studies but also focuses mostly on patients. A search through the PubMed database ${ }^{9}$ for the terms "suffering" and "providers" in the title yielded only four results, none of which focused on the suffering of providers. A search query in the same database using "suffering" in the title field and "doctors" in the general field yielded 222 results, most of which also focused on patient suffering. Yet, as Katie Watson points out, "surely we can advocate for the humanity of patients without denying the humanity of those who treat them" (2011:38). In other words, while we can all agree that focusing on patients and patient suffering is crucial, if we want to understand the culture of medicine more broadly, we should also allow ourselves to focus on other stakeholders within the health care system, including physicians, nurses, and other staff. In reality, for example, physician power is highly context-specific. Just as professors who work at universities are perceived by the public to have power but are subject to many institutional limitations in their work, the power of doctors who work in hospitals is highly regulated. Physicians are subjected to a shifting and complex matrix of competing claims by administrators, state and federal government regulations, insurance companies, ethical guidelines, patient wishes, and the contingencies of what can actually be accomplished.

Statistics illustrate that physicians suffer. Consider the high suicide rates. The suicide rate for female physicians is 250 percent to 400 percent higher than females in other professions and 70 percent higher among male physicians than males in other professions (Brunk 2015). These statistics suggest a high degree of suffering among doctors, presuming reasonably that a person who commits suicide suffered beforehand. ${ }^{10}$ Mark Harris, a neurosurgical anesthesiologist in Salt Lake City whom I interviewed in 2018, characterized the state of physician suicides as "an epidemic," with about 400 physician suicides per year in the United States, the equivalent of approximately two classes of medical school students nationwide (Harris 2018). Physician suicide is pervasive enough that the American Foundation for Suicide Prevention produced a documentary in 2008 entitled Struggling in Silence: Physician Depression and Suicide. The word "silence" in the title indicates the degree to which it is taboo for physicians to talk about their personal problems, and it reinforces the point that it is considered unseemly and unprofessional for physicians to admit that they need help simply because their job is to care for sick others. It is common knowledge that denying or ignoring one's own sickness has negative consequences, yet this feature is built into and perpetuated by members of the profession.

Further, physicians witness every aspect of human suffering, sometimes on a daily basis, depending on their specialty. But as noted in the Journal of Palliative Care, the effect of witnessing suffering on the part of experienced clinicians largely has been unexplored (Breaden et al. 2012). An editorial in the pulmonary journal Chest similarly notes that patient suffering affects doctors, but the little existing literature focuses mostly on practical ways to fix the problem, such as offering more support to staff (van Staa, Visser, and van der Zouwe 2000; Meier, Back, and Morrison 2001) 
or noting that not much is done in terms of training physicians on how to deal with it (Curtis and Levy 2014; Outram and Kelly 2014).

Some studies suggest connections between the witnessing of patient suffering and physician burnout, which is a pervasive problem, or they suggest that witnessing suffering can lead to symptoms of grief and depression. Studies conclude unsurprisingly that physicians who work with the terminally ill have high rates of burnout and stress. One sample study found that nearly 25 percent of oncologists (a specialty with a particularly high death rate among patients) experienced some kind of psychiatric disorder arising from grief, and that nearly 50 percent of physicians who worked with the terminally ill were affected themselves (Redinbaugh et al. 2001:187-8). Another study, which focused on health care workers in the palliative care unit of the National Cancer Institute in Portugal, concluded that such work induced physical and mental stress due to workers' involvement in the suffering of patients and families (Kappaun and Gomez 2013:2,549). In their study of nurses, Steeves, Kahn, and Benoliel link patient suffering to work burnout by noting that nurses appropriate patient suffering, which then leads to burnout (1990; see also Kahn and Steeves 1994), and this is likely true for physicians as well.

This body of research does not characterize burnout, grief, and depression as suffering, or the result of suffering. But, in a crucial link between the two, Thomas Cole and Nathan Carlin note that "burnout, we believe, is also a euphemism for what many physicians experience as a crisis of meaning and identity" (2009:1,414). A crisis of meaning and identity is a metaphysical crisis, one in which core beliefs are questioned or undermined and one's relevancy is called into doubt. Recall that Cassell's model for suffering specifically identified a crisis of meaning as an important element; this idea is reformulated in Kahn and Steeves, who identify threat to identity as an element of suffering as well (1995:12). Combined with stress, grief, and depression, burnout can arguably be considered an experience of suffering on the part of care providers, though it is usually labeled as something else.

In sum, suffering in the medical field generally is understood as something existing in patients, as something associated with an individual, and as something to be treated clinically. Yet as a holistic, intersubjective phenomenon, suffering in medicine can extend to physicians, who may suffer because of difficult, strenuous working conditions; because they are encouraged by their occupational culture to deny their own needs; because of their professional role as witnesses to suffering; and because their job is to relieve it. Suffering is built into the very nature of health care work.

\section{Suffering, Laughter, and Transformation}

So what might suffering have to do with humor and laughter? One important point that Cassell makes is that pain and suffering are interpretations of what is going on. He writes: "The pain [e.g., suffering] as experienced is itself the interpretation" ([1991] 2004:268). People experience pain in various ways-ways that are connected to individual experiences, beliefs, and values. Cassell notes that if the beliefs and values associated with pain and suffering shift, then the actual experience of pain and suffering can shift as well. Cassell argues that if culturally relevant meaning can be 
assigned to pain and illness, suffering lessens because suffering entails hopelessness and meaninglessness. Meaningfulness alters medical facts.

The most important type of culturally relevant meaning assigned to suffering and through which it is transformed into "something else" is religious meaning. The first truth of Buddhism is that "life is suffering," while the Judeo-Christian theological idea of theodicy directly addresses the question of suffering by asking: "If God is good, why do people suffer?" In the Judeo-Christian tradition, suffering is considered to be a test, punishment, correction, or opportunity. The Book of Job is a primary text on suffering; Job's suffering at the hands of God is explained as a test and opportunity for growth. Personal transformation can be one outcome of suffering-one becomes a better human being, rearranges life priorities, or maintains a closer relationship with God.

Assigning religious meaning lessens suffering for many people. Knowing that one's suffering has transcendent implications helps some people interpret their suffering as having a higher purpose that goes beyond the immediate painful, injurious, or grievous experience. Reframing suffering as an experience with a purpose by linking it to a deity as religion does may counteract the meaninglessness, hopelessness, shame, and impending sense of total destruction of the self that define suffering. When people who are suffering accept a religious connection to their experience, they move from a state of meaninglessness to meaningfulness and, in doing so, move from hopelessness to hope. Even if they die as a result of their suffering (as with serious illness), the sense of impending total destruction of the self is eased if they see death as having a purpose that transcends the mundane world.

Western medical contexts are decidedly secular, and an alternative way in which suffering can be transformed into "something else" is through humor and laughter. Folklore scholarship has long revealed that laughter, humor, and joking behaviors are traditional mechanisms for changing given meanings. Humorous devices temporarily overturn, reframe, and challenge situations by inverting given hierarchies and values. They reveal the ambiguity of language and provide opportunities to imbue situations with alternate interpretations. In speaking of verbal jokes, a genre designed to confound categories and generate laughter, Christie Davies notes that "jokes are a brief time off from the everyday inhibitions and restrictions that bind the ways we speak. Jokes mean we can indulge in ambiguity, blatant and obvious departures from reality or logic, absurdity, impropriety, and the utterly shocking" (2011:3). Jokes allow us to speak the forbidden, temporarily rearrange given categories, and produce brief transformations or alternate interpretations. As noted above, there is a robust and extensive body of humor among medical professionals that is well-documented in both scholarly and popular literature. Physicians who work in teaching hospitals may perform various kinds of verbal speech play, including jokes, puns, nicknames, slang, toasts, funny personal stories, and other routines; they may also engage in practical jokes and pranks, poke fun at co-workers and administrators, and parody work situations through song and dance routines on YouTube and other media (Gabbert 2018). This body of humor functions temporarily to transform dominant frameworks of interpretation that assign meanings of sadness, grief, and failure to patient pain, illness, and death, thus shifting the actual experience of work-related suffering by changing its meaning. 
There is, for example, a large and well-documented corpus of medical humor about death. Doctors work profoundly with the body, and there is a comic orientation toward the body in medical humor, particularly toward what Bakhtin ([1968] 1984) called the lower material bodily stratum (the reproductive organs and digestive system), an orientation that makes medical humor frequently off-color, scatological, and sexual. Death, however, is the most dire, real, and constant threat to the body in medical work, and it is unsurprising that a large quantity of folklore surrounds death.

I believe that one of the earliest spaces in which medical humor about death and the body begins to emerge is in gross anatomy class, a first-year medical school requirement in which an entire human body is dissected. Gross anatomy is very intense, differing for obvious reasons from the other science classes that first-year medical students take, such as microbiology or pharmacology. While most medical students have completed dissections prior to medical school, this is often the first official time that students come face-to-face with death and the human body on a daily basis. Students are required to accomplish a full dissection including head, face, hands, and genitalia. Veins, organs, nerves, and other tissues are removed, dissected, and examined, and some parts, such as the head, must be severed using a bone saw. As one medical student blithely noted, anatomy lab is a proving ground for black humor since "it's a bunch of dead bodies around you . . . so it's kind of a surreal environment" (Anonymous 2012c). My spouse took gross anatomy in medical school at Indiana University in 1999 and explained that everyone in the group had to remember to keep their mouths closed and not talk while the bone saw was being used to avoid getting bone chips in the mouth-and, of course, when one student didn't stop talking and did actually get a bone chip in his mouth, everyone laughed and made fun of him. Body parts are stored until the end of the semester when they can be disposed of properly; when I visited the gross anatomy lab in 1999, I observed that they were stored in a large covered bucket under the table. The smell of formalin, the main chemical used to preserve the bodies, is pervasive and overwhelming, and students come home "smelling of death," as one explained to me. Students may also find unexpected body modifications, such as tattoos or scars, as well as objects, like breast or testicular implants in the body, and these modifications may be the subject of jokes and laughter. Gross anatomy is, without a doubt, an extreme situation in which students confront death starkly and must overcome fear, repulsion, horror, and ambivalence to do what is likely taboo the world over: take apart a human being bit by bit.

Though certainly not all students use humor, many do respond to such situations in traditionalized, comic ways. A common response is to name or nickname the body (Hafferty 1988) since donors are anonymous. One student explained in an interview that every anatomy lab group named its bodies. His group nicknamed its body "Fred," but he explained that the names were not always real names since they often derived from the physical characteristics of the donor. "One was like the Green Man, the Green Lantern, whatever. Because he was green. I don't know why he was green. ... He was green" (Anonymous 2012c). Another group named its body "Julia" because it had painted fingernails. The reference was to Julia Roberts and the character (a sex worker) she played in the 1990 movie Pretty Woman. Yet another group named its 
body after porn star Ron Jeremy since the donor had congestive heart failure, resulting in an extremely swollen and enlarged penis. Students may also celebrate the body's (fictional) birthday.

Even students who do not engage directly in humor and jokes in gross anatomy acknowledge that the atmosphere is quite casual. One student characterized herself as someone who held the highest respect for body donors and who would be easily offended by inappropriate or disrespectful humor. Even she, however, did not recall an instance during her gross anatomy lab where she felt offended by laughter. "It definitely was like a very like, relaxed, casual atmosphere. I guess I sort of told myself that that's what our body donor would have wanted. She would have wanted us to enjoy it" (Anonymous 2012a). Another student similarly emphasized the importance of having respect for the body donor, saying that her group's humorous comments mostly consisted of joking attempts to explain why they couldn't find a particular structure: "We said, 'Well, she didn't have one of those!"' (Anonymous 2012b).

Another, less common, traditional response is to play tricks using anatomical specimens as props. One medical student quoted above told me that he switched hearts between two different bodies because his group's heart looked quite different; the purpose was to mess with his buddy's dissection. This same student also said that he snuck up behind a friend, "the smartest guy in the class," who happened to be dissecting alone with headphones on, in the lab near Halloween. The prankster floated a lab skull in his hand, right outside the boundary of the student's vision. The student saw it out of the corner of his eye, screamed, and jerked suddenly with scalpel in hand, almost cutting the prankster. "I realized in hindsight that this was really dumb," he said (Anonymous 2012c). Such behaviors fit easily into an established folkloristic body of work that connects death to humor, practical jokes, play, and laughter (Narváez 2003a, 2003b; Miller 2012; Blank 2013; Marsh 2015). This type of humor has been identified as being important to the socialization of medical students (Hafferty 1988; Becker 1993), but I also believe that it is the first time in which students start using humor and laughter as a resource for the pain and discomfort inflicted on them by their training.

The specter of death does not stop with gross anatomy class, but follows medical professionals throughout their career. As medical students progress in their training, they become more and more responsible for diagnosing, understanding, and monitoring their patients' health. Patients are sick, perhaps terminally ill, and physicians, who are legally responsible for their patients, are supposed to figure out what is wrong and help them if possible. Physicians therefore sometimes feel like death is a bad outcome, or even a foe that the doctor is supposed to vanquish or stave off. Dr. Harris explains:

I always joke with patients: "My job is to put you to sleep, keep you alive, and wake you up again." And so for me, my job is to keep people alive. And so if someone dies in and around my gravitational pull, I feel a little-sad, obviously, but, like, disappointed in myself. Because if I'm seeing someone, it is because there is hope and there is a plan and there is a way out. And there is a cure potential and at least a potential of staving off of death. And if someone dies then we have failed in our intent. (2018) 
Dr. Harris also noted that only one person had ever died on his watch in the OR and, in that case, the patient was so sick that the team was "tilting at windmills." Death is also a taboo topic in American culture generally (Samuel 2013), and Americans tend to believe they have the right to long, healthful, and youthful lives. Growing old and dying are unacceptable options, and this orientation affects medical care.

Unsurprisingly, then, there are numerous slang terms for death among medical professionals, many of which have been amply documented in previous studies. While terms can be localized and may vary from hospital to hospital, in general physicians (as well as sometimes the general public) are familiar with them not only nationally but sometimes even internationally. ${ }^{11}$ This is because physician culture, including folklore, is occupationally based; it is less tied to geographical location than it is to the structure of education and training. Physicians have an extremely lengthy training period and train in different parts of the country. A physician may attend a 4-year medical school in one state, a 3-year residency in another state, and a fellowship of 1 to 4 years or more-plus additional specialization-in yet another state before finally settling on a permanent place of work. In this way, physicians differ from other health care providers who do not train for as long and who are not required to move around for training purposes, and who may have a different, though likely related, occupational culture.

Some examples of slang words for "death" are "cooled" and "tagged" (Coombs et al. 1993:994). These terms evoke images of a morgue: the word "cooled" references the fact that the temperature in morgues is kept low, while "tagged" refers to the identification marker (the tag) on the body. Other terms related to death, such as "to box," "dirt nap," and "planted," are slang terms for burial (Coombs et al. 1993:994). The term "box" refers to the coffin in which bodies are placed before burial, while "dirt nap" and "planted" refer to the earth in which bodies are buried. Additional slang terms for "died" include "croaked," "kicked the bucket," "checked out," "crashed," "ate it," "went belly up," "bit the big one," and "bit the long weenie" (994). Some phrases are quite specific to the medical profession. "To die a Harvard death," for example, means that a patient's lab values were normal (that is, perfect, like Harvard University), but the patient died anyway (Burson-Tolpin 1989:287). A common phrase that I have often heard in medical circles is "circling the drain," or CTD for short, which is applied to a patient who is clearly dying but who is not dead yet. The idea is that a dying person is swirling inevitably toward death, circling closer and closer, much like water swirling around a drain before finally being sucked down the drain hole.

Physicians also have comic terms for patients who are either dying or dead. Because physicians are taught to have the highest respect for their patients, speaking humorously about dying or dead patients not only breaks cultural taboos by making death a lighthearted subject, but also targets a category of persons who are usually accorded great value and respect. In England, for example, an elderly patient might be diagnosed as having TMB, which stands for "too many birthdays" (Fox et al. 2003:188), a term I have also heard used in the United States. In this case, the only problem the patient has is advanced age. Normally, elderly people are given a lot of respect in face-to-face situations. In this case, however, the term makes fun of the elderly and therefore inverts normal social and professional etiquette. Another British term 
is "T. F. BUNDY," which stands for "Totally fucked but unfortunately not dead yet" (Fox et al. 2003:188) and refers to a patient who is still alive but medically has little hope. Again, this term inverts expected etiquette. It not only suggests that it would be better for the patient to be dead, but also does so using vulgar language. A final, related term from Great Britain is "GPO," which stands for "Good for parts only" (Fox et al. 2003:185). This term refers to dying patients; the implication is that parts of their body, such as transplant organs, may be of use to others. ${ }^{12}$

Slang terms for death do not address suffering directly, but they do index feelings of futility and hopelessness, criteria associated with suffering. A doctor's job is to stave off death and illness, yet patients can and do remain sick and sometimes die, so it is not uncommon for physicians, depending on their specialty, to feel like they are responsible or perhaps like they even have failed in their duties, as Dr. Harris noted above. Even if a physician helps one patient get well, that patient will be replaced by another one who may not get well. Medical students explained to me that working with the sick and terminally ill can be relentless because of the organizational structure of hospital work. Sometimes a single patient is replaced by many patients, all of whom may have overwhelming, unsolvable problems. The cycle is repeated endlessly, and the workload is incessant. One's duty as a doctor can feel hopeless, meaningless, and overwhelming, with seemingly no way out. When I asked Dr. Harris if he ever felt overwhelmed during his training, he replied, "Oh absolutely, most of the time. . . For me it felt like ... running ahead of like an avalanche. Like I was sprinting as hard as I could and looking over my shoulder and those rocks were just almost right there" (2018). Slang or humorous terms for death and dying or dead patients allow care providers a way to speak about a taboo topic and temporarily transform official interpretations of death as a serious or tragic event, a perceived failure on the part of the physician, or something he or she is helpless against to something funny or even banal.

The examples from gross anatomy class perform a similar transformative function. Gross anatomy lab is difficult academically, technically, and often emotionally or psychologically. Students stare death in the face every time they walk into the lab, and they engage in acts for which they would be arrested outside of a medical school. Jeannie Thomas explores the emergence of laughter in response to unfunny stories of appalling situations, such as family narratives about suicide attempts and abuse. Drawing on Kristeva, she argues that "laughter at the painful often signals the recognition of ... a situation that threatens abjection, a state where we recognize with horror that we can be undone" (Thomas 1997:59). In other words, encounters with the abject-such as a corpse-can lead to laughter. Laughing at the characteristics of a cadaver, naming or nicknaming it, or joking about it re-humanizes an anonymized donor, reminding students that their lab specimens were once also living people with all the identity features and associations that living people have. To name is both to label and to control: in the face of anonymity, the horror of death, and a potential state of abjection in which one is confronted with a horrific "undoing," some medical students resort to traditionalized forms of laughter. This is particularly important as the dissection progresses, since the donor comes to look less and less like a human being over time. 
Physicians acknowledge that humor and laughter make work more bearable. They do not state that it relieves their suffering per se, since physicians do not see themselves as sufferers-they identify as people who relieve suffering and who, in fact, rarely even get sick (see above). Yet humor and laughter emerge almost immediately once training begins (in the gross anatomy lab) and continue to develop over time, so there is clearly a relationship between working conditions and laughter. Dr. Harris initially completed an ER residency in Scotland in the 1980s. He describes the grueling circumstances of training at that time, which continue in many medical graduate training programs today.

Residency was really for me-and I think my wife would confirm this-was really where it got hard. When I did my residency my first six months I averaged 120 hours a week in the hospital. We were on call one in three. And what that meant is you stayed in house [in the hospital] every third night, including the days on either side of it. And the same for the weekends. You'd go in on Saturday morning and you'd come home on Monday night. And it was busy: you were working, you were not sleeping. (Harris 2018)

Dr. Harris also stated that humor is directly correlated to working conditions and acknowledges that the forms of humor change as physicians advance in their training. As working conditions change, humor changes as well.

I've actually come to the conclusion that I think there has been several phases of humor ... at least that I have observed in my medical career. Initially as an intern and as a resident in Scotland, where the circumstances were a lot harder, the hours were a lot longer, [residents] were less supported ...-the humor was a lot more bitter and kind of gallowsian? ... I think that was because it was tough.... We were kind of almost lashing out a little bit at circumstances and medicine and supervisors and our patients sometimes.... As circumstances get better, as people get a little more comfortable or happy in their careers, the humor mellows a bit. (Harris 2018)

I then asked Dr. Harris whether or not the humor lessened once physicians were out of training.

I think it changes. So, you know, I do-I think that when you're a med student, when you're an intern and any time during your training, and it's human nature right? When you're scared, when you're frustrated, the humor becomes more of a defense mechanism. It becomes more of, either to keep things away, or to some degree make them less scary. I think as you become more comfortable, as you move through your career, the humor becomes more of a way of discussing the situation we're in. A way of, for me anyway, a way of talking about the differences between specialties, between approaches, a kind of making light a little bit of some of the sadder parts of our job. Not as a defense mechanism but as a kind of ... sharing. (Harris 2018)

Historical examples also provide evidence that suffering can serve as a primary context for laughter. Steve Lipman has documented the extensive nature of humor and laughter used by Jews and others during the Holocaust, one of the world's greatest 
examples of suffering. Lipman writes: "Jokes were made about every facet of life and death in the Nazi era. . . . Starvation, disease, beatings, murder, and every form of persecution were grist for the victim's joke mill” (1991:19). His book catalogs Naziera jokes, witticisms, satirical folk songs, and the like, and he notes repeatedly that Holocaust humor was born of sorrow. "By appreciating the humor from the period we are not laughing at the victims or their suffering; we are simply recognizing that laughter was a part of their lives, a part nurtured by their suffering" (Lipman 1991:9; emphasis added). Lipman also insists that Holocaust humor was not gallows humor but rather a laughter of hope and resistance based in horror. He writes: "Life is often tragic, but its pathos reflects itself most distinctly in jokes. There is behind the comic façade not only something serious ... but sheer horror" (12). Lipman's work clearly illustrates that contexts of suffering can generate humor and laughter; indeed, in such contexts, it is the only way out: "In freedom, humor is a mere luxury," writes former Nazi prisoner Natan Sharansky. "In prison, it's the only weapon. The moment you can laugh at them you are free" (quoted in Lipman 1991:134). While the conditions of modern medical practice obviously are quite different from the conditions of Nazi Germany, the notion that humor and laughter free people from terrible conditions is similar.

Some studies of occupational folklore also illustrate interconnections between suffering and laughter, though they are not framed as such. Claire Schmidt documents the extensive use of "sick" humor by prison guards (2017), while Tim Tangherlini documents the sick/funny stories told by paramedics, who are often the first responders to terrible crime scenes and horrific auto accidents (1998). These studies do not identify suffering as a primary context for humor, but prisons arguably are institutions designed to increase suffering as a form of punishment, and it is likely that this institutional purpose affects not only the prisoners but also the guards. Indeed, Schmidt's informants told her over and over again that laughter and humor were survival tools. Tangherlini does not elaborate on the humor used by paramedics, but he repeatedly points out the horrific (abject) nature of the situations in which paramedics find themselves and at which they consistently laugh.

Returning to the joke with which this article began then, what the joke accomplishes seems less offensive when it is contextualized within a framework of suffering and laughter. First, the joke addresses the topic of suffering from both the perspective of the patient and the caregiver. The joke describes a nightmare, the worst situation imaginable for all parties involved. According to the scenario set up by the joke, the mother has survived the stroke but is doomed to suffer and live as a "vegetable,"13 while the son will suffer and die. The son will die more quickly than the mother as a result of the stress of having to give so much care. In addition, his care is futile, since the mother will never improve and will never recognize her son. The picture painted is hopeless; it is one of endless pain, anguish, expense, and meaninglessness. It is a picture of suffering.

Additionally, this unhappy situation is the result of successful medical care. As noted above, the impulse in Western medicine is to preserve life at all costs, and the death of a patient is considered a bad outcome. But many physicians and other care providers fully understand that preserving life at all costs can be a problem. For example, it can lead to painful, unsuccessful procedures being performed on patients. In the 
most extreme cases, such as the one described in this joke, preserving life at all costs can increase suffering, a direct violation of the principal precept of bioethics, which is primum non nocere (first, do no harm). The situation, then, is the direct result of occupational paradoxes.

The final line "HA! Just kidding, she's dead" is the most shocking. First, the line reframes the given nightmarish situation, revealing it to be false: the doctor has played a prank on his patient's son (Bauman 1986; Marsh 2015). In real life, a doctor would not joke about a patient's condition to a loved one, so this is one of the strongest taboos that the joke breaks. Additionally, the actual words "Ha! Just kidding" render this reframing purposefully insensitive. The proper response to death is to offer consolation, so this line highlights a presumed lack of feeling or callowness on the part of the physician. But from the doctor's point of view in this case, death is, in fact, the "good news," because it is an escape from the suffering that has been described. The sadness and narrative tension that build as the doctor describes in horrific detail the length and nature of suffering the son must endure is suddenly gone, released by death with a single line. This idea directly contradicts and inverts the dominant perspective that life must be preserved at all costs, but it is also why the joke is shocking to people who work outside the medical field. Most Americans are not immersed in contexts of sickness, suffering, and death in their everyday work, and this perspective is foreign to them.

\section{Conclusion}

In this article, I have argued that a culture of suffering permeates medical training and some forms of practice for physicians, particularly those at teaching hospitals, and this culture of suffering is a primary context for medical humor and the medical carnivalesque. While the functions of medical humor are relatively well understoodrelief of anxiety, expression of hostility, a defense mechanism, and a way of speaking about taboo topics-suffering as a primary condition for medical humor has not been identified. In contexts of suffering, physicians use humor as a traditional means of transformation; in Cassell's framework, they assign comic meaning to various dimensions of suffering and, in doing so, temporarily transform it into something else.

Medical humor is secular, but there are parallels between the transformations of suffering accomplished by humor and the transformations of suffering accomplished by faith. In his book Redeeming Laughter (1997), Peter Berger makes the strongest case for links between the comic and the sacred, despite the seeming incongruity between the two and the fact that the Judeo-Christian tradition rarely utilizes the comic or addresses laughter (Houck 2007; Joeckel 2008).${ }^{14}$ Berger draws parallels between the ways in which both faith and the comic offer new perspectives on the ordinary world. Both are transformations, breaks from ordinary reality, a shift of insight into "what is going on." Berger writes that ordinarily the comic registers in a "lower key," meaning that it reframes ordinary life temporarily but does not offer "transcendence," which he defines as indexing another world that is redemptive, that has been made whole, or in which the mysteries of the human condition are abolished. Berger considers this "world beyond" a register of the "second/higher key" (1997:190ff.); it is the one in which faith generally operates. 
Yet even in the lower key, the comic can point toward higher spheres of meaning. Berger notes, for example, that "the comic presents a world without pain. . . . It is, above all, an abstraction from the tragic dimension of human experience" (Berger 1997:194). His example is the clown who is beaten over and over again, but apparently feels no pain and continues to get up to receive yet another beating. The audience laughs because pain does not exist for the clown. As soon as the clown feels pain, the scene is no longer funny. Berger writes: "Generally, any comedy turns into tragedy as soon as real suffering, real pain, is allowed to enter into it," and, from a religious standpoint, "the promise of redemption is always a world without pain" (195). In other words, the comic beating of the clown operates in the lower key, but because the clown is free from pain, it points toward the higher, more transcendent sphere, which is always free of suffering.

Berger's example of the beating of the clown who feels no pain again reminds me of contexts for Bakhtin's carnivalesque laughter, many examples of which were predicated on death, violence, and the dismemberment of the body, and many others of which were predicated on medical quackery (Bakhtin [1968] 1984). Bakhtin insists that carnivalesque laughter is transformative and ambivalent. Scholars have focused on the celebratory and potentially revolutionary aspects of carnivalesque laughter and have explained descriptions of its horrors as evidence of rebirth. Perhaps what is implied in Bakhtin's work but not stated directly is that carnivalesque laughter is directly related to real pain, death, and suffering, experiences that religion traditionally identifies as having potential for growth. Humor, such as that which arises in the practice of medicine and is part of the medical carnivalesque, also accomplishes the transformation of suffering, a phenomenon that not only undergirds medical comedy and the clinical vernacular but appears to have deep historical roots.

\section{Coda}

In an op-ed published in the Atlantic in 2012, the author Samuel Shem offered his thoughts on The House of God 34 years after its publication, and he commented specifically on the role of suffering. He remarked that he didn't recognize the effect his book was having until his publisher forwarded him a line from an intern at the VA hospital in Tulsa, Oklahoma. The intern had written to Shem: "If [it] weren't for your book I'd kill myself." Reflecting on the life history of this novel—which originally was censored by medical school deans-Shem characterizes it as a "fiction of resistance" to the inhumane treatment of both patients and doctors. Shem notes that he has added four more "laws" over the years to the original 13 outlined in his book, stating that, of these new four, the law of "making connections" in order to stave off suffering is important. He concludes his op-ed noting:

This is the culmination [of] my learning so far. All of us will suffer-it's not optional. Some will suffer more, some less. The issue isn't suffering, it's how we walk through it, and how we help others walk through it. If we decide to walk through suffering alone-"stand tall, draw a line in the sand, tough it out"-we will suffer more, and spread more suffering around. This is where we health-care folks come in-this is our job, to be with others in caring. (Shem 2012) 


\section{Acknowledgments}

I am grateful for the suggestions made by the anonymous reviewers of this article and to the editors of the Journal of American Folklore. I also am grateful to Dr. Anton Salud, who helped develop the idea of the medical carnivalesque, to Dr. Mark Harris, Dr. Bill Walsh, and to the medical students who participated in the interviews.

\section{Notes}

1. Oxford English Dictionary, s.v., "gallows," OED Online.

2. Personal communication by email, February 10, 2015.

3. Oxford English Dictionary, s.v., "schadenfreude," OED Online.

4. The term "appropriate incongruity" comes from Elliott Oring's elaboration of incongruity theory, which is the explanation that two ideas that are seemingly opposite are paired together to generate humor. Oring elaborates that the joke is funny because the elements are not only incongruous but also somehow work; hence, the term "appropriate incongruity" $(2003,2011)$.

5. Oxford English Dictionary, s.v., "suffer," OED Online.

6. World Health Organization, WHO Definition of Palliative Care, http://www.who.int/cancer/ palliative/definition/en/ (accessed June 2, 2019).

7. Carolyn Ware found similarly distressing experiences with veterinarians who often bond emotionally and spiritually with their animal patients, despite the rhetoric of scientism and emotional detachment found in histories of veterinary practice. As one informant explained, "every day we take home that loss" (quoted in Ware 2018:25).

8. It is important to note that for many, if not most people in the health professions, caring for people is rich and rewarding work. The purpose of this article is not to suggest that all health care workers automatically suffer because of their working conditions; the contexts of health care work vary greatly, as do individuals and their levels of resilience. Rather, the idea in this article is simply to point out that the effects of witnessing suffering and caring for sufferers can and does take an emotional toll, and the phenomenon of suffering permeates the profession in multiple ways.

9. See PubMed, the US National Library of Medicine, National Institutes of Health database, https:// www.ncbi.nlm.nih.gov/pubmed/.

10. One possibility for the large disparity in suicide rates between physicians and other professions is that, because of their medical knowledge and training, doctors may simply be more successful at committing suicide than other people.

11. For example, when I gave a version of this paper in Kyoto, Japan, for the Vernacular Culture Study Group in 2017, one Japanese member of the audience said that she had relatives in the medical field and the humor was familiar to her.

12. For additional examples of medical slang and medical language, see Coser (1959), Becker (1993), Dans (2002), George and Dundes (1978), Gordon (1983), Leiderman and Grisso (1985), McCrary and Christensen (1993), Odean (1995), Taller (1983), Winick (2004).

13. The term "vegetable" is a lay/vernacular term and not a medical term. A physician would likely never actually use the term "vegetable" to describe a patient's clinical condition in a professional setting, although it might be used in informal circumstances.

14. Joeckel points out, for example, that the rule of St. Benedict, which was established in the sixth century, specifically forbids laughter: "Of speech provoking laughter we condemn everywhere to eternal exclusion" (Benedict quoted in Joeckel 2008:416). Although St. Benedict banished laughter, there were other saints known for their laughter, such as Margery Kempe and St. Bridget, who insisted that heaven was a merry place; their laughter, however, was strongly critiqued by the Church. (My thanks to Dr. Christine Cooper-Rompato for these medieval examples.) Peter Berger also points out a few brief examples of the comic in Christianity, including tropes of folly in the New Testament and the Paschal laughter of the medieval church and Erasmus's In Praise of Folly, first printed in 1511, which is one of the few publications in which folly is viewed as benign (Berger 1997). Folklorists also have illustrated connections between laughter and religious/sacred contexts: in the Narváez volume, for example, Illana 
Harlow (2003) sets the context of Irish traditions of practical jokes at wakes within a larger religious belief system, noting the contrast of play with the official seriousness of death and elite religious ideology, while Donald Cosentino outlines a logic in Haitian thought between death and laughter as manifested in the Gedes, "whose antics transform the cemetery into Haiti's theater of the absurd" (Cosentino 2003:243).

\section{References Cited}

Anonymous. 2012a. Recorded interview by Lisa Gabbert, March 21.

Anonymous. 2012b. Recorded interview by Lisa Gabbert, March 21.

Anonymous. 2012c. Recorded interview by Lisa Gabbert, March 22.

Anonymous. 2012d. Recorded interview by Lisa Gabbert, April 10.

Bakhtin, Mikhail. [1968] 1984. Rabelais and His World, trans. Hélène Iswolsky. Bloomington: Indiana University Press.

Bauman, Richard. 1986. Story, Performance, and Event: Contextual Studies of Oral Narrative. Cambridge: Cambridge University Press.

Becker, Howard S. 1993. How I Learned What a Crock Was. Journal of Contemporary Ethnography 22(1):28-35.

Berger, Jeffrey T., Jack Coulehan, and Catherine Belling. 2004. Humor in the Physician-Patient Encounter. Archives of Internal Medicine 164(8):825-30.

Berger, Peter L. 1997. Redeeming Laughter: The Comic Dimension of Human Experience. New York: Walter de Gruyter.

Blank, Trevor J. 2013. The Last Laugh: Folk Humor, Celebrity Culture, and Mass-Mediated Disasters in the Digital Age. Madison: University of Wisconsin Press.

Brady, Erika, ed. 2001. Healing Logics: Culture and Medicine in Modern Health Belief Systems. Logan: Utah State University Press.

Breaden, Katrina, Meg Hegarty, Kate Swetenham, and Carol Grbich. 2012. Negotiating Uncertain Terrain: A Qualitative Analysis of Clinicians' Experiences of Refractory Suffering. Journal of Palliative Medicine 15(8):896-901.

Briggs, Charles L. 2012. Toward a New Folkloristics of Health. Journal of Folklore Research 49(3):319-45.

Brunk, Doug. 2015. Physician Suicide: Common and Closeted. Chest Physician 10(2):20, 22.

Burson-Tolpin, Anne. 1989. Fracturing the Language of Biomedicine: The Speech Play of US Physicians. Medical Anthropology Quarterly 3(3):283-93.

_ 1990. "Fascinomas" and "Horrendiomas": The Occupational Language, Humor, and Speech Play of American Physicians. PhD diss., University of Pennsylvania.

Campion-Vincent, Véronique. 2005. Organ Theft Legends, trans. Jacqueline Simpson. Jackson: University Press of Mississippi.

Cassell, Eric J. [1991] 2004. The Nature of Suffering and the Goals of Medicine. New York: Oxford University Press.

Cole, Thomas R., and Nathan Carlin. 2009. The Suffering of Physicians. The Lancet 374(9,699):1,414-5.

Coombs, Robert H., Sangeeta Chopra, Debra R. Schenk, and Elaine Yutan. 1993. Medical Slang and Its Functions. Social Science \& Medicine 36(8):987-98.

Cosentino, Donald J. 2003. Exit Laughing: Death and Laughter in Los Angeles and Port-au-Prince. In Of Corpse: Death and Humor in Folklore and Popular Culture, ed. Peter Narváez, pp. 239-60. Logan: Utah State University Press.

Coser, Rose Laub. 1959. Some Social Functions of Laughter: A Study of Humor in a Hospital Setting. Human Relations 12(2):171-82.

Curtis, J. Randall, and Mitchell M. Levy. 2014. Our Responsibility for Training Physicians to Understand the Effect Patient Death Has on Them: The Role of the Intensivist. Chest 145(5):932-4.

Dans, Peter E. 2002. The Use of Pejorative Terms to Describe Patients: "Dirtball” Revisited. Proceedings (Baylor University Medical Center) 15(1):26-30.

Davies, Christie. 2011. Jokes and Targets. Bloomington: Indiana University Press.

Donnelly, William J. 1986. Medical Language as Symptom: Doctor Talk in Teaching Hospitals. Perspectives in Biology and Medicine 30(1):81-94. 
Fox, Adam T., Michael Fertleman, Pauline Cahill, and Roger D. Palmer. 2003. Medical Slang in British Hospitals. Ethics \& Behavior 13(2):173-89.

Gabbert, Lisa. 2018. Folk Drama. In “The Challenge of Folklore to the Humanities," ed. Dan Ben-Amos. Special issue, Humanities 7(2). https://www.mdpi.com/2076-0787/7/1/2.

Gabbert, Lisa, and Anton Salud. 2009. On Slanderous Words and Bodies Out-of-Control: Hospital Humor and the Medical Carnivalesque. In The Body in Medical Culture, ed. Elizabeth Klaver, pp. 209-27. Albany: State University of New York Press.

George, Victoria, and Alan Dundes. 1978. The Gomer: A Figure of American Hospital Folk Speech. Journal of American Folklore 91(359):568-81.

Goldstein, Diane E. 2004. Once Upon a Virus: AIDS Legends and Vernacular Risk Perception. Logan: Utah State University Press.

Gordon, David Paul. 1983. Hospital Slang for Patients: Crocks, Gomers, Gorks, and Others. Language in Society 12(2):173-85.

Hafferty, Frederic W. 1988. Cadaver Stories and the Emotional Socialization of Medical Students. Journal of Health and Social Behavior 29(4):344-56.

Harlow, Ilana. 2003. Creating Situations: Practical Jokes and the Revival of the Dead in Irish Tradition. In Of Corpse: Death and Humor in Folklore and Popular Culture, ed. Peter Narváez, pp. 83-112. Logan: Utah State University Press.

Harris, Mark. 2018. Recorded interview by Lisa Gabbert, September 6, Salt Lake City, UT.

Houck, Anita. 2007. The Ambiguous Laughter of Reconciliation: Comic Theodicy in Modern Literature. Religion and Literature 39(1):47-78.

Hufford, David. 1994. Folklore and Medicine. In Putting Folklore to Use, ed. Michael Owen Jones, pp. 117-35. Lexington: University Press of Kentucky.

. 1998. Folklore Studies Applied to Health. Journal of Folklore Research 35(3):295-313.

Joeckel, Samuel. 2008. Funny as Hell: Christianity and Humor Reconsidered. Humor: International Journal of Humor Research 21(4):415-33.

Kahn, David L., and Richard H. Steeves. 1994. Witnesses to Suffering: Nursing Knowledge, Voice, and Vision. Nursing Outlook 42(6):260-4.

. 1995. The Significance of Suffering in Cancer Care. Experience of Cancer and Its Meaning 11(1):916.

Kappaun, Nádia Roberta Chaves, and Carlos Minayo Gomez. 2013. The Task of Caring for Terminally Ill Cancer Patients. Ciência \& Saúde Coletiva 18(9):2,549-57.

Kitta, Andrea. 2012. Vaccinations and Public Concern in History: Legend, Rumor, and Risk Perception. New York: Routledge.

Lee, Jon D. 2014. An Epidemic of Rumors: How Stories Shape Our Perception of Disease. Logan: Utah State University Press.

Leiderman, Deborah B., and Jean-Anne Grisso. 1985. The Gomer Phenomenon. Journal of Health and Social Behavior 26(3):222-32.

Lipman, Steve. 1991. Laughter in Hell: The Use of Humor during the Holocaust. Northvale, NJ: Jason Aronson. Marsh, Moira. 2015. Practically Joking. Logan: Utah State University Press.

McCrary, S. Van, and Rasmus Corlin Christensen. 1993. Slang "on Board": A Moral Analysis of Medical Jargon. Archives of Family Medicine 2(1):101-5.

McCreaddie, May, and Sally Wiggins. 2008. The Purpose and Function of Humour in Health, Health Care and Nursing: A Narrative Review. Journal of Advanced Nursing 61(6):584-95.

Meier, Diane E., Anthony L. Back, and R. Sean Morrison. 2001. The Inner Life of Physicians and Care of the Seriously Ill. JAMA 286(23):3,007-14.

Miller, Montana. 2012. Playing Dead: Mock Trauma and Folk Drama in Staged High School Drunk-Driving Tragedies. Logan: Utah State University Press.

Narváez, Peter, ed. 2003a. Of Corpse: Death and Humor in Folklore and Popular Culture. Logan: Utah State University Press.

- 2003b. Tricks and Fun: Subversive Pleasures at Newfoundland Wakes. In Of Corpse: Death and Humor in Folklore and Popular Culture, ed. Peter Narváez, pp. 113-39. Logan: Utah State University Press.

O'Connor, Bonnie Blair. 1994. Healing Traditions: Alternative Medicine and the Health Professions. Philadelphia: University of Pennsylvania Press. 
O’Connor, Bonnie Blair, and David Hufford. 2001. Understanding Folk Medicine. In Healing Logics: Culture and Medicine in Modern Health Belief Systems, ed. Erika Brady, pp. 13-35. Logan: Utah State University Press.

Odean, Kathleen. 1995. Anal Folklore in the Medical World. In Folklore Interpreted: Essays in Honor of Alan Dundes, ed. Regina Bendix and Rosemary Lévy Zumwalt, pp. 137-52. New York: Garland.

Oring, Elliott. 2003. Engaging Humor. Urbana: University of Illinois Press.

- 2011. Parsing the Joke: The General Theory of Verbal Humor and Appropriate Incongruity. Humor: International Journal of Humor Research 24(2):203-22.

Outram, Sue, and Brian Kelly. 2014. "You Teach Us to Listen, ... but You Don't Teach Us about Suffering": Self-Care and Resilience Strategies in Medical School Curricula. Perspectives in Medical Education 3:371-8.

Parsons, Genevieve Noone, Sara B. Kinsman, Charles L. Bosk, Pamela Sankar, and Peter A. Ubel. 2001. Between Two Worlds: Medical Student Perceptions of Humor and Slang in the Hospital Setting. Journal of General Internal Medicine 16(8):544-9.

Penson, Richard T., Rosamund A. Partridge, Pandora Rudd, Michael V. Seiden, Jill E. Nelson, Bruce A. Chabner, and Thomas J. Lynch. 2005. Laughter: The Best Medicine? The Oncologist 10(8):651-60.

Redinbaugh, Ellen M., James M. Schuerger, L. Leonard Weiss, Adam Brufsky, and Robert Arnold. 2001. Health Care Professionals' Grief: A Model Based on Occupational Style and Coping. Psycho-Oncology 10(3):187-98.

Samuel, Lawrence R. 2013. Death, American Style: A Cultural History of Dying in America. Lanham, MD: Rowman \& Littlefield.

Schmidt, Claire. 2017. If You Don't Laugh, You'll Cry: The Occupational Humor of White Wisconsin Prison Workers. Madison: University of Wisconsin Press.

Shem, Samuel. [1978] 2003. The House of God. New York: Delta Trade Paperbacks.

- 2012. Samuel Shem, 34 Years After 'The House of God.' The Atlantic, November 28. http://www .theatlantic.com/health/archive/2012/11/samuel-shem-34-years-after-the-house-of-god/265675/.

Sobel, Rachel K. 2006. Does Laughter Make Good Medicine? New England Journal of Medicine 354(11):1,114-5.

Steeves, Richard H., David L. Kahn, and Jeanne Quint Benoliel. 1990. Nurses' Interpretation of the Suffering of Their Patients. Western Journal of Nursing Research 12(6):715-31.

Struggling in Silence: Physician Depression and Suicide. 2008. American Foundation for Suicide Prevention. Documentary film, $60 \mathrm{~min}$.

Taller, Stephen L. 1983. More Common Patient-Directed Pejoratives Used by Medical Personnel. Maledicta: The International Journal of Verbal Aggression 7:38-40.

Tangherlini, Timothy R. 1998. Talking Trauma: A Candid Look at Paramedics through Their Tradition of Tale-Telling. Jackson: University Press of Mississippi.

Thomas, Jeannie B. 1997. Featherless Chickens, Laughing Women, and Serious Stories. Charlottesville: University Press of Virginia.

van Staa, Anne Loes, Adriaan Visser, and Nicolette van der Zouwe. 2000. Caring for Caregivers: Experiences and Evaluation of Interventions for a Palliative Care Team. Patient Education and Counseling 41(1):93-105.

Ware, Carolyn E. 2018. Veterinary Medicine and the Spiritual Imagination: A Body-Centered Approach. Journal of Folklore Research 55(2):9-37.

Watson, Katie. 2011. Gallows Humor in Medicine. Hastings Center Report 41(5):37-45.

Wear, Delese, Julie M. Aultman, Joseph Zarconi, and Joseph D. Varley. 2009. Derogatory and Cynical Humour Directed towards Patients: Views of Residents and Attending Doctors. Medical Education 43(1):34-41.

Winick, Stephen D. 2004. "You Can’t Kill Shit": Occupational Proverb and Metaphorical System among Young Medical Professionals. In What Goes Around Comes Around, ed. Kimberly J. Lau, Peter Tokofsky, and Stephen D. Winick, pp. 86-106. Logan: Utah State University Press. 